\title{
RESEARCH
}

\section{Initial Validation of an Instrument for Measuring Entrepreneurial and Intrapreneurial Intentions in Student Pharmacists}

\author{
Nazneen Fatima Shaikh, BPharm, ${ }^{\mathrm{a}}$ Mona Nili, PharmD, MBA, MS, ${ }^{\mathrm{a}}$ Nilanjana Dwibedi, PhD, MBA, ${ }^{\mathrm{a}}$ \\ S. Suresh Madhavan, $\mathrm{PhD}, \mathrm{MBA}^{\mathrm{b}}$ \\ ${ }^{a}$ West Virginia University School of Pharmacy, Morgantown, West Virginia \\ ${ }^{\mathrm{b}}$ University of North Texas, System College of Pharmacy, Fort Worth, Texas \\ Submitted April 19, 2019; accepted September 29, 2019; published July 2020.
}

\begin{abstract}
Objective. To develop a questionnaire for measuring entrepreneurial and intrapreneurial intentions among student pharmacists and to identify characteristics and personality traits that are associated with these intentions.

Methods. A 105-item survey instrument was developed and administered to all Doctor of Pharmacy (PharmD) students (incoming to third year) at a large public university. It consisted of nine scales pertaining to entrepreneurism including previously validated and some newly developed scales adapted for use among student pharmacists. Data analysis consisted of factor analysis to determine scale constructs, reliability assessment, and systematic item-reduction analysis. Multiple linear regression and structural equation modeling was used to determine and confirm the association of personality traits and demographic characteristics with entrepreneurial and intrapreneurial intentions.

Results. Of 289 students surveyed, 286 useable survey instruments were included in the analysis. Factor analysis was conducted for each scale, and items that did not load on their theorized factor or had cross-loadings above the permissible limits were removed, reducing the survey to 69 items. Findings demonstrated that gender, joint degree program, and autonomy were significant predictors of entrepreneurial intentions, and achievement motivation, leadership self-efficacy, and problemsolving were significant predictors of intrapreneurial intentions.

Conclusion. A multi-dimensional questionnaire to measure entrepreneurial and intrapreneurial intentions of student pharmacists was developed and a few key predictors of such intentions were identified. When fully validated, the questionnaire may be used in pharmacy schools for several purposes, including in the PharmD admission process to gain additional insights into a student's potential to become a future innovative entrepreneurial or intrapreneurial practitioner.
\end{abstract}

Keywords: entrepreneurship, intrapreneurship, pharmacist, personality traits, questionnaire

\section{INTRODUCTION}

Entrepreneurism is about developing, organizing, and managing a business venture. An entrepreneur takes calculated risks to create an innovative solution for a societal problem and promotes it to the community as a self-sustaining business venture and, in the process, creates jobs. Intrapreneurs are individuals who can excel at their work within the constraints of an organization, take shared risks, and develop innovative new services or products that are profitable to the organization. In pharmacy, an entrepreneur or intrapreneur

Corresponding Author: Nazneen Fatima Shaikh, West Virginia University School of Pharmacy, Robert C. Byrd Health Sciences Center [North], P.O. Box 9510, Morgantown, WV 26506-9510. Tel: 304-293-1442. Email:

ns0067@mix.wvu.edu. would likely develop new services based on the unmet needs of patients in a community or apply innovative ideas to add or improve services already being provided by an organization. ${ }^{1,2}$ For example, soon after the Medicare Modernization Act was passed, a student pharmacist-led Medicare Part D planning clinic was established to help older adults make informed decisions on choosing the most appropriate Medicare Part D plans for their needs. Creation of the clinic resulted in a potential annual savings to the patients of more than $\$ 28,000$ and $100 \%$ of the patients reporting very satisfied with the service. ${ }^{2}$ According to entrepreneurism research, several individual characteristics and personality traits are instrumental in motivating entrepreneurial and intrapreneurial intentions and behavior. ${ }^{3-6}$ Intrapreneurs and entrepreneurs have overlapping traits but few differences. An intrapreneur is employed in an 


\section{American Journal of Pharmaceutical Education 2020; 84 (7) Article 7624.}

organization and takes shared risks with their employer as compared to an entrepreneur who owns the business and takes complete responsibility of the risk of possible financial failure. ${ }^{7}$ Another key difference between them relates to their attitude towards business ownership, with intrapreneurs found to be less inclined towards ownership as compared to entrepreneurs. ${ }^{8}$ The rapid growth of hospital, department store, grocery, and chain pharmacies in the past three decades have led to an increase in the number of employee pharmacists. ${ }^{9}$ This has made the term intrapreneurship highly relevant to the pharmacy profession today to describe those who develop innovative patient-care services within institutional or organizational settings. ${ }^{10,11}$

Measuring the entrepreneurial and/or intrapreneurial potential of student pharmacists is important for the role of pharmacists in the present healthcare environment. The forces affecting the health care system, including escalating healthcare costs, the increasing burden of chronic diseases, primary care provider shortages, uneven affordability of health care, and poor health outcomes, have provided an opportunity for the pharmacy profession to reposition itself to be a problem solver in the healthcare system, particularly of those problems related to the appropriate use of medications. Development of innovative patient-care services and practice models that can improve healthcare quality and outcomes and reduce costs require entrepreneurial and intrapreneurial abilities among pharmacists. To capture the essence of pharmacist involvement in a patient care activity, the Joint Commission of Pharmacy Practice has created the Pharmacists' Patient Care Process (PPCP). The PPCP is a collaborative care framework for delivering patient care, and includes such tasks as collecting and assessing patient information, planning and implementing patient-specific care, and subsequently monitoring patients to ensure that appropriate therapeutic outcomes are achieved. ${ }^{12}$ To emphasize its importance for future pharmacists, the Accreditation Council of Pharmacy Education's Standards 2016 (specifically, Standard 10.8) require that schools and colleges of pharmacy develop their curricula to teach PPCP and assess students' abilities to provide such patient-care services. In addition, Standard 4.3 on innovation and entrepreneurship stipulates that, "...the graduate is able to engage in innovative activities by using creative thinking to envision better ways of accomplishing professional goals." 13

With the evolving role of the pharmacist, major national organizations (American Pharmacists Association and American Association of Colleges of Pharmacy) are working toward including pharmacists on the federal list of recognized healthcare providers. ${ }^{14}$ The Pharmacy and
Medically Underserved Areas Enhancement Act has been introduced in the US Congress with bipartisan support to amend the Social Security Act section 1861(s)(2) to add pharmacists to the list of recognized health care providers to deliver patient care in medically underserved communities and be eligible for reimbursement for patientcare services. ${ }^{15}$ With such emerging opportunities for pharmacists to play a role in helping to address unmet healthcare needs and the potential for even newer roles, the need for pharmacists with vision, innovative thinking, and propensity for risk taking has never been greater. However, a qualitative study published in 2016 indicated that pharmacists' have often taken a back seat in instances of assuming leadership roles in times of major decision-making, being wary of the possibilities of future conflicts. ${ }^{16}$ This avoidance may be attributed to risk aversion among pharmacy students reported in several studies. ${ }^{4,17,18}$ Another study by Rosenthal and colleagues found that community pharmacists perceive themselves as "dispensers of medications" instead of a "patient healthcare provider."19 Findings from these studies indicate perhaps an absence of or diminished entrepreneurial personality traits in pharmacists. Because research has repeatedly established personality traits as one of the most important predictors of successful entrepreneurs, ${ }^{4,20-22}$ students with an inclination towards or students with inherent entrepreneurial/intrapreneurial personality traits may be more likely to develop innovative practices or embrace a more patient-oriented role in the future.

A recent study evaluating student pharmacists' professional identities in Australia, found that pharmacy was not the first career choice for most of the students. ${ }^{23}$ The study also reported that many students were entering the pharmacy program with little or no understanding of the profession. In the United States, the admission criteria for pharmacy schools has traditionally focused on prepharmacy science courses, pharmacy college admission test scores, and overall grade point average in general education coursework. The admission interviews are generally focused on ascertaining written and verbal communication skills and student aptitude and preparation for a pharmacy career. Given the emphasis on science accomplishments, the admission process may be unintentionally excluding those students who are likely to become risk-taking innovators/entrepreneurs in the pharmacy profession. Having reliable and validated measures of identifying entrepreneurial and/or intrapreneurial traits and intentions among incoming student pharmacists may be necessary for the development of future pharmacists to succeed in a profession that increasingly needs more risktakers and innovators for its future success. Thus, the objectives of this pilot study were to: develop a questionnaire 


\section{American Journal of Pharmaceutical Education 2020; 84 (7) Article 7624.}

to measure entrepreneurial and intrapreneurial intentions of student pharmacists and identify the characteristics and personality traits among student pharmacists that are associated with entrepreneurial and intrapreneurial intentions.

\section{METHODS}

A cross-sectional study design was used to survey all incoming (P0) and first- (P1), second- (P2) and third- (P3) year students of the PharmD program at West Virginia University. In this pilot study, there were two dependent variables, entrepreneurial intentions and intrapreneurial intentions. A questionnaire was developed using previously established and validated scales. A thorough review of the literature initially identified a total of 19 constructs associated with entrepreneurial and intrapreneurial intentions. Given time and respondent fatigue considerations, the research team narrowed down the constructs to nine as being most commonly associated with the above intentions and relevant to pharmacy. The questionnaire was divided into two parts, the first part consisted of 90 items measuring nine personality traits constructs along with entrepreneurial and intrapreneurial intentions. The items were measured on a seven-point Likert scale (strongly disagree $=1$, strongly agree $=7$ ). The personality traits constructs included were locus of control, innovativeness, autonomy, risk taking, proactiveness, achievement motivation, people liking, problem-solving, and leadership self-efficacy. These traits were included based on their association with entrepreneurial or intrapreneurial intentions, past literature, and empirical knowledge. ${ }^{24-38}$ Each of the scales used were well-established in the literature, with good validity and reliability, and accounted for 50 items. The scales used for each construct are provided in Table 1 along with one sample item for each. The key dependent variables, entrepreneurial intentions and intrapreneurial intentions were assessed by items adapted from a study by Douglas and colleagues. ${ }^{8}$ Entrepreneurial intention was measured using four items (eg, "I want to be self-employed within two years of graduation") and intrapreneurial intention was measured using three items (eg, "I want to manage a division [within a pharmacy or company] that is set up to exploit a radical innovation in patient care"). The second part of the questionnaire consisted of categorical items addressing demographic and educational characteristics including age, gender, race, annual income, and marital status, along with questions related to participating in a joint degree program and a question about whether any family member was involved in business.

Students from each of the four PharmD classes participated in the anonymous and voluntary survey. The data collection was carried out in four different classroom settings with instructor approval at West Virginia University, which resulted in a convenience sample of all PharmD students during the spring and fall 2018 semesters. The pilot study was acknowledged as exempt by the Institutional Review Board of West Virginia University. The voluntary nature of the questionnaire, consent in the form of participation, and anonymity was assured prior to the questionnaire being distributed along with the instructions for completion.

Descriptive statistics were used to describe the study participants. All the items of the questionnaire were evaluated for face validity by the authors. A few minor modifications were suggested to increase relevancy to student pharmacists. The reliability of the constructs was determined using Cronbach coefficient alpha.

The underlying structure of original scales was confirmed using principal component analysis (IBM SPSS

Table 1. Nine Personality Trait Constructs Included in the Study to Assess the Entrepreneurial and Intrapreneurial Intentions of Student Pharmacists

\begin{tabular}{|c|c|c|}
\hline Construct & Validated Scale & Sample Item \\
\hline Locus of control & Rotter I-E Scale ${ }^{24}$ & My life is determined by my own actions. \\
\hline Innovativeness & Jackson Personality Inventory (JPI) ${ }^{25}$ & I often surprise people with my novel ideas. \\
\hline Risk-taking & Willingness to Take Risk scale ${ }^{32}$ & $\begin{array}{l}\text { I am not willing to take risks when choosing a job or a } \\
\text { company to work for. }\end{array}$ \\
\hline Proactiveness & Proactive Personality Scale (PPS) ${ }^{33}$ & I excel at identifying opportunities. \\
\hline People liking & Filsinger Liking scale ${ }^{35}$ & $\begin{array}{l}\text { Sometimes when people are talking to me, I find myself } \\
\text { wishing that they would leave. }\end{array}$ \\
\hline Problem solving & Problem-Solving scale ${ }^{36}$ & I am always successful in solving problems. \\
\hline Leadership self-efficacy & Leadership Self-Efficacy scale (LSE) ${ }^{37}$ & $\begin{array}{l}\text { I can successfully manage relationships with all the } \\
\text { members of a group. }\end{array}$ \\
\hline
\end{tabular}




\section{American Journal of Pharmaceutical Education 2020; 84 (7) Article 7624.}

version 25.0 Armonk, NY). ${ }^{39}$ When the underlying structure was confirmed, we retained the structure and reduced the number of items for each sub-factor. We dropped items that did not contribute to a sub-factor structure and failed to meet the minimum requirement of having a primary factor loading of 0.4 or above and no cross-loading of 0.3 or above. We then selected the items with the highest loadings for each sub-factor maintaining the underlying structure of the construct. The Eigen values for all the factors were greater than 1 . Significant differences in traits by demographic and other characteristics were determined using $t$ tests and oneway ANOVA $(p \leq .05)$, and correlations with the dependent variables evaluated by using Pearson coefficient for interval variables and Spearman coefficient for categorical variables. Multiple linear regressions were used to determine the key traits associated with the entrepreneurial and intrapreneurial intentions of the students.

Structural equation modeling was conducted using STATA Release 15, (StataCorp LLC. College Station, TX) as a confirmatory factor analysis. ${ }^{40}$ It included all the significantly correlated personality traits and background variables, with entrepreneurial and intrapreneurial intentions as dependent variables. All the constructs were included as latent variables measured by items as the observed variables. The constructs had a direct pathway to the dependent variables. Parameter estimates were obtained using the weighted least squares estimators, and standard errors for the indirect effects were estimated using the theta method. Goodness of fit indices included the comparative fit index (CFI) and the root-mean-square error of approximation (RMSEA).

\section{RESULTS}

Of the 289 students surveyed, 286 submitted completed questionnaires. A majority of the students were female $(59 \%)$, white $(87 \%)$, and were $22-25$ years of age $(52 \%)$. While only $7 \%$ of the respondents were enrolled in joint degree programs (mostly MBA), $26 \%$ had a family member involved in a business (Table 2).

Factor analysis indicated loading patterns consistent with the theorized factor structure for all the scales. The 10-item modified Rotter's Locus of Control scale indicated loading on three components with a few items having cross-loadings of above $0.30 .^{24}$ Four items were removed that had high cross-loadings and/or low interitem correlation $(<0.20)$ and providing the best possible Cronbach alpha value if that item was deleted. The new scale had six items: three each for internal locus of control and external locus of control. The internal consistency of the new scale (0.74) as measured by Cronbach alpha was comparable to that of the original scale (0.77). Similarly, the eight-item Jackson Personality Inventory Manual for
Table 2. Demographics of Participants in the Study to Assess the Entrepreneurial and Intrapreneurial Intentions of Student Pharmacists $(\mathrm{N}=286)$

\begin{tabular}{lc}
\hline & No. (\%) \\
\hline Sex & \\
Female & $175(59)$ \\
$\quad$ Male & $124(41.5)$ \\
Age & \\
$18-21$ & $115(38.7)$ \\
$22-25$ & $155(52.2)$ \\
26 and more & $27(9.1)$ \\
Race & \\
White & $263(86.8)$ \\
Non-white & $28(9.2)$ \\
Marital Status & \\
Single & $258(85.7)$ \\
$\quad$ Married/in relationship & $43(14.3)$ \\
Annual Family Income & \\
Below \$30,000 & $215(73.9)$ \\
Above \$30,000 & $76(26.1)$ \\
Attending Joint Degree MBA & \\
$\quad$ Yes & $20(6.6)$ \\
No & $281(93.4)$ \\
\hline
\end{tabular}

innovativeness was evaluated and reduced to a three-item new scale with factor loading ranging from 0.93 to 0.97 , Eigen value 2.7 , and explaining $90 \%$ of the variance. ${ }^{25}$ The new Cronbach alpha value of the scale was 0.82 , better than the 0.79 of the original scale. The five-item autonomy scale and three-item risk-taking scale were kept intact as the reduction of even one item was disrupting to the underlying structure of the constructs. ${ }^{31,32}$ The 10-item shortened Bateman and Grant's Proactive Personality Scale was reduced to a five-item scale with factor loadings ranging from 0.66 to 0.79 and a Cronbach alpha value of 0.80 (previous 0.86 ). ${ }^{33}$

The Work Preference Inventory-10, the 15-item Filsinger Liking Scale, and the 21-item Leadership SelfEfficacy scale were reduced to five-item, seven-item, and 12-item scales, respectively. ${ }^{35-37}$ With the reduction of items, the Cronbach alpha for these three scales changed from 0.65 to $0.71,0.85$ to 0.83 , and 0.91 to 0.90 , respectively. Furthermore, we added three items from the achievement motivation scale to the problem-solving scale because of the similar underlying structure of the factors. So, the three-item scale was increased to a sixitem problem-solving scale (Cronbach alpha $=0.79)$. The risk-taking scale was only three items and therefore was not modified (Cronbach alpha $=0.71$ ). The item reduction process facilitated removal of less reliable and redundant items, leaving a total of 69 -items in the questionnaire (Table 3). 


\section{American Journal of Pharmaceutical Education 2020; 84 (7) Article 7624.}

Table 3. Personality Trait Scales in the Study Assessing the Entrepreneurial and Intrapreneurial Intentions of Student Pharmacists $(\mathrm{N}=286)$

\begin{tabular}{lccc}
\hline Construct & Items, No. & Mean (SD) & Cronbach alpha $(\boldsymbol{\alpha})^{\text {a }}$ \\
\hline Entrepreneurial Intentions & 4 & $3.0(1.5)$ & .9 \\
Intrapreneurial Intentions & 3 & $4.1(1.5)$ & .95 \\
Locus of control & 6 & $5.4(.8)$ & .74 \\
Innovativeness & 3 & $4.2(1.4)$ & .82 \\
Autonomy & 4 & $4.5(.9)$ & .72 \\
Risk Taking & 3 & $3.9(1.2)$ & .71 \\
Proactiveness & 5 & $5.1(.9)$ & .80 \\
Achievement Motivation & 5 & $4.9(.9)$ & .71 \\
People Liking & 7 & $4.9(1.1)$ & .83 \\
Problem Solving & 6 & $4.8(.9)$ & .79 \\
Leadership Self-Efficacy & 12 & $5.3(.8)$ & .90
\end{tabular}

${ }^{a}$ Mean on a scale of 1 to 7

As expected, entrepreneurial and intrapreneurial intention scales were found to be unidimensional, with excellent Cronbach alpha values of 0.95 and 0.91 , respectively. ${ }^{8}$ The mean score for entrepreneurial intention was 3.0, while that for intrapreneurial intention was 4.1, both with a range from 1 to 7 . The Pearson and Spearman correlations for entrepreneurial and intrapreneurial intentions was conducted with all the personality traits. Expectedly, the two intentions were highly correlated (Pearson product moment correlation $=0.43$ ). Moreover, entrepreneurial intention was significantly correlated with autonomy, risk-taking propensity, proactiveness, problem-solving, leadership self-efficacy, gender, and joint degree program. Intrapreneurial intention was significantly correlated with autonomy, proactiveness, achievement motivation, problem solving, leadership self-efficacy, gender, and joint degree program.

We used multiple linear regression (MLR) to identify the key traits associated with entrepreneurial and intrapreneurial intentions for all student pharmacists. We developed two models: the entrepreneurial intention model and the intrapreneurial intention model. We then used mean score of the four items constituting the entrepreneurial intention factor and the mean score of the three items constituting intrapreneurial intention factor as the dependent variables in the two regression models, respectively. The independent variables were the same for each model, including the nine personality traits and the demographic and educational variables.

In the entrepreneurial intention model (Table 4), leadership self-efficacy, autonomy, and problem-solving personality traits were significantly associated $(p \leq .05)$. Additionally, from the demographics and background variables, gender and joint degree programs were significantly associated with entrepreneurial intention. Together, all the variables explained $16.8 \%$ of the variance.
The results of the intrapreneurial intention model is shown in Table 4. Leadership self-efficacy, problemsolving, autonomy, and achievement motivation were significantly associated with intrapreneurial intention $(p \leq .05)$. The results of the MLR indicated that the four personality traits explained $18.2 \%$ of the variance. Family member involvement in business was not associated with either intention in this study.

We included only seven constructs (variables that demonstrated significant correlations with entrepreneurial intention and intrapreneurial intention) measuring latent personality traits and observed educational and demographic characteristics in structural equation modeling (Figure 1). The model demonstrated that gender, joint degree program, and autonomy were significant predictors of entrepreneurial intention. Achievement motivation and leadership self-efficacy and problem-solving were found to be significant predictors of intrapreneurial intention. The structural equation modeling had goodnessof-fit indices of $\mathrm{CFI}=0.81$ and $\mathrm{RMSE}=0.63$.

\section{DISCUSSION}

This study is the beginning of a program of inquiry into identifying and nurturing future entrepreneurs and intrapreneurs in pharmacy. Several new terms, including "pharmapreneur," "medipreneur," and "valuetrained pharmacists" have been increasingly appearing in pharmacy blogs and news in the past few years. ${ }^{41,42}$ However, the literature regarding these terms has not yet been formally developed/expanded beyond the blogs. Thus, this is the first study to identify associations between personality traits and entrepreneurial and intrapreneurial intention and will add some background to these terms in peer-reviewed literature. We followed a rigorous process to develop a 69-item EntrepreneurialIntrapreneurial Pharmacist Questionnaire (EIPQ) to 


\section{American Journal of Pharmaceutical Education 2020; 84 (7) Article 7624.}

Table 4. Association Between Entrepreneurial Intention and Intrapreneurial Intention of Student Pharmacists with Personality Traits and Demographic and Educational Characteristics

\begin{tabular}{llllc}
\hline Predictors & B & SE B & $\boldsymbol{\beta}$ & $\boldsymbol{p}$ Value \\
\hline Entrepreneurial Intention & & & & .15 \\
$\quad$ Constant & 1.42 & .1 & -.21 & $<.001^{\mathrm{a}}$ \\
$\quad$ Gender & -.63 & .17 & .15 & $.01^{\mathrm{b}}$ \\
$\quad$ Leadership Self-efficacy & .31 & .12 & .16 & $.006^{\mathrm{b}}$ \\
Autonomy & .27 & .01 & .13 & $.026^{\mathrm{c}}$ \\
Problem solving & .22 & .01 & -.12 & $.039^{\mathrm{c}}$ \\
$\quad$ Joint degree program & -.68 & .33 & & .03 \\
Intrapreneurial Intention & & & $.001^{\mathrm{a}}$ \\
$\quad$ Constant & -1.56 & .73 & .21 & $.011^{\mathrm{c}}$ \\
$\quad$ Leadership Self-efficacy & .43 & .13 & .15 & $.017^{\mathrm{c}}$ \\
Problem solving & .25 & .01 & .14 & $.03^{\mathrm{c}}$ \\
\hline Autonomy & .23 & .01 & .13 & \\
$\quad$ Achievement Motivation & .21 & .01 & & \\
\hline
\end{tabular}

Abbreviations: $\mathrm{B}=$ unstandardized beta coefficient, $\mathrm{SE} \mathrm{B}=$ standard error coefficient, $\beta=$ standardized beta coefficient

${ }^{\mathrm{a}} p \leq .001$

${ }^{\mathrm{b}} p \leq .01$

${ }^{\mathrm{c}} p \leq .05$

measure entrepreneurial and intrapreneurial intention of student pharmacists and associated personality traits by employing factor analysis, MLR, and confirming the results with structural equation modeling.

The EIPQ consists of 11 different constructs, with each having acceptable to very good reliability. Mean student scores on most personality traits were on the positive side, indicating that the students possessed these critical personality traits. The mean scores of entrepreneurial and intrapreneurial intention indicated that overall students had ambivalence toward entrepreneurism or intrapreneurism at the present stage of their training. The slightly higher mean score for intrapreneurial intention may suggest that students slightly preferred the idea of working within an organization rather than on their own. This finding is consistent with the published literature demonstrating mixed results in the student pharmacists' intentions towards entrepreneurism, with more studies reporting negative intentions. ${ }^{17,43,44}$ A study evaluating student pharmacists' intentions based on theory of planned behavior reported negative beliefs, attitudes, and intentions towards pharmacy ownership. ${ }^{17}$ In the study, students reported lacking knowledge and skills to become an entrepreneur, which may suggest a problem with the curriculum in pharmacy schools. There may be a need to add or revise the curriculum to make entrepreneurism content and skills more prominent to students. Overall, the students in this study possessed few personality traits associated with becoming an entrepreneur or intrapreneur, with greater than 5.0 mean scores on locus of control, leadership self-efficacy, and proactiveness, but low mean scores on risk-taking propensity and innovativeness. This suggests that the students in this specific university may have preferred a safe, secure, and reliable job setting and were risk averse. Also, this response may be explained by the influence caused by the transition of the role of the pharmacist from an independent pharmacy owner to a more employee-pharmacist role working within an institution or chain pharmacy. ${ }^{45,46}$ Furthermore, with the increased competition for independent pharmacies from large chain pharmacies, shrinking prescription drug margins, fewer owner-pharmacist role models, and stiff regulatory and competitive environment, students may prefer the job safety of working in an institutional or chain pharmacy where such risks directly to them are minimal. Risk aversion among pharmacy students is well documented in the literature. Several studies have provided potential solutions that can be employed to mitigate this problem in pharmacy students. ${ }^{4,17,18}$ Some strategies include education, active co-curricular activities requiring risk-taking behavior from students, and demonstration of risk-taking to the students by conducting seminars with real-life risk-taking entrepreneurs. Elective courses that focus on creative thinking, risk-taking, and initiating innovative projects may also be helpful. ${ }^{47}$

As established in the literature, we found several traits associated with entrepreneurial and intrapreneurial intentions overlapping. Research indicates that entrepreneurial and intrapreneurial individuals possess high risk tolerance and aspire for more independence. ${ }^{48-51}$ In this study, we found autonomy to be statistically associated with both entrepreneurial and intrapreneurial intentions, 


\section{American Journal of Pharmaceutical Education 2020; 84 (7) Article 7624.}

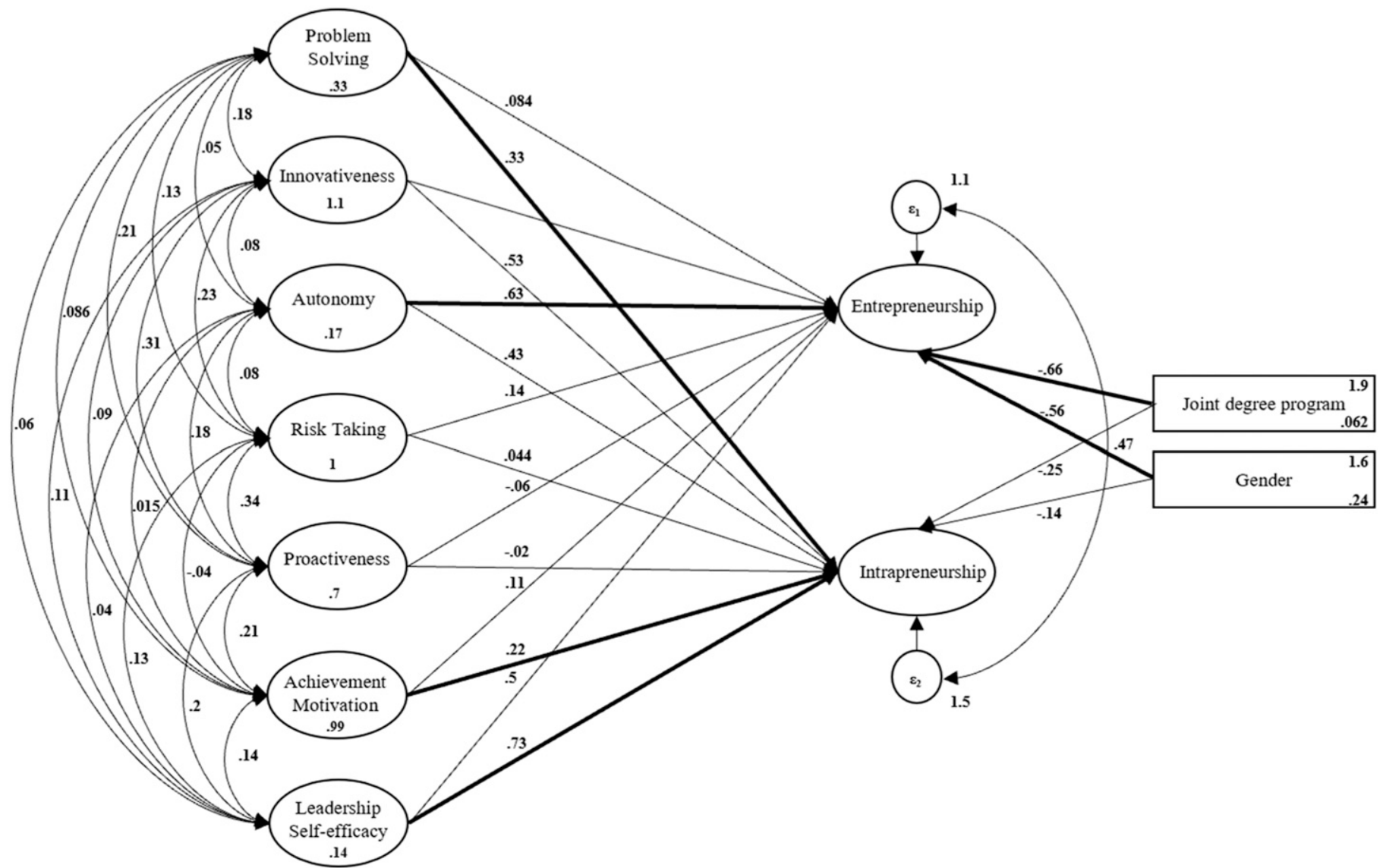

Figure 1. Structural Equation Modeling. The relationship of personality traits, educational characteristics, and demographic variables with student pharmacists' entrepreneurial and intrapreneurial intentions.

$\mathrm{CFI}=0.81, \mathrm{RMSEA}=0.064, \chi^{2}(1042)=2348.9, p \leq .001$ (bold line: significant predictors)

but autonomy was a stronger predictor of entrepreneurial intention than of intrapreneurial intention. However, risktaking propensity was not a significant predictor and that possibly depicts the shift in the role of pharmacists mentioned earlier. The leadership self-efficacy scale combined leadership and self-efficacy in one scale, thereby allowing the measurement of both constructs within one scale. ${ }^{37}$ We found leadership self-efficacy to be a significant predictor of both entrepreneurial and intrapreneurial intention. However, it was a stronger indicator of intrapreneurial intention. Problem-solving was found to be a significant predictor of both. Previous studies have demonstrated that problem-solving is a key trait of a person in a leadership position, such as an entrepreneur or intrapreneur. ${ }^{37,52,53}$

Student pharmacists who had enrolled in a joint degree program were more likely to have high entrepreneurial intention. The majority of the student pharmacists (93.4\%) pursuing or interested in joint degree programs were enrolled in a joint business degree. This decision suggests a likely inclination towards business or entrepreneurship. Therefore, we were not surprised that the joint degree program was a significant predictor of higher entrepreneurial intention. Female student pharmacists made up the majority of the study sample, which is consistent with national trends of an increased proportion of women entering the profession. They were found to be more likely to have higher entrepreneurial intention than men. This is consistent with studies that report that the percentage of female entrepreneurs in pharmacy has increased significantly. ${ }^{54,55}$

In trying to distinguish between students with high entrepreneurial intention and those with high intrapreneurial intention, we found that students with high achievement motivations were more likely to have high intrapreneurial intention. Specifically, a student with high achievement motivation along with leadership and problem-solving traits and a desire for autonomy will be more likely to have intrapreneurial intention. The role of achievement motivation is vital in this association as an intrapreneur must go beyond the traditional expected duties and role as an employee pharmacist, deal with the political and resource challenges to explore opportunities and innovate to introduce a new pharmacy service that is 


\section{American Journal of Pharmaceutical Education 2020; 84 (7) Article 7624.}

not currently being offered. Ross and Unwalla have portrayed the intrapreneurial personality to include motivation to solve problems and being ambitious in nature. ${ }^{56}$ Spinelli and Adams recognize motivation to excel as one of the key aspects of quality of intrapreneurism. ${ }^{57}$ Achievement motivation is also crucial in entrepreneurship, but that motivation arises from the fear of risk of failure of the business. However, for intrapreneurs, the risk is shared with the organization.

The key personality traits identified in the MLR were further confirmed through structural equation modeling. Although, leadership self-efficacy and problem solving were not significantly associated with a student having entrepreneurial intention and autonomy was not significantly associated with intrapreneurial intention, structural equation modeling was able to confirm all other key personality traits while taking into account the interrelated dependent relationship between entrepreneurial and intrapreneurial intention in the model. The covariance of entrepreneurial and intrapreneurial intention could have played a significant role in the model. While MLR is limited to assessing one relationship at a time, structural equation modeling can efficiently estimate a series of interrelated dependent relationships concomitantly. Additionally, MLR is unable to directly estimate potential relationships in a model that are based on theoretical background and, at the same time, fit data. Structural equation modeling is more effective than MLR in developing a parsimonious model because it can evaluate the interaction effects among the variables. Thus, the structural equation modeling approach that examines multiple dependence relationships is considered efficient in addressing complicated personality and behavioral issues.

Consistent with the study by Hermansen-Kobulnicky and colleagues, we support broadening the horizon of pharmacy education with appropriate inclusion of entrepreneurial awareness and training. ${ }^{5}$ Students passing examinations and getting residencies seems to be the growing emphasis in pharmacy education. However, without entrepreneurial mindsets, students may not be motivated to innovate and create new job opportunities. Most student pharmacists consider entrepreneurship to be owning an independent pharmacy store; however, this it is not the only application of entrepreneurial skills in the marketplace for pharmacists. There are opportunities emerging for innovative non-dispensing, patient-care services such as cognitive or consultative services related to chronic disease management and medication therapy management, which in the future may allow pharmacists to become successful entrepreneurs or intrapreneurs. ${ }^{58,59}$ Moreover, pharmacist should start to explore the profession beyond the easily accessible but slowly decreasing corporate jobs where pharmacists have the least autonomy and control of their work.

This study has several limitations. The EIPQ has been tested in only one pharmacy school with a modest sample size and sample variability. The EPIQ needs to be validated for criterion and predictive validity by testing in samples of known entrepreneurial and intrapreneurial pharmacists in both community and institutional settings. It needs further testing in multiple sites across different types (eg, public/private, geographical regions) and longitudinally to determine how predictive the questionnaire is of student pharmacist intentions translating into actions. Also, EIPQ is designed to identify intentions in students, and these may not equate with future behavior.

The EIPQ incorporates both entrepreneurial and intrapreneurial intention giving the advantage of measuring student pharmacists' interest in promoting pharmacy services either independently or as part of a pharmacy organization by using just one questionnaire. The EIPQ also includes key personality traits associated with entrepreneurs and intrapreneurs. This composite measure of entrepreneurial intention, intrapreneurial intention, and personality traits facilitates active evaluation of the required personality traits for students possessing entrepreneurial and intrapreneurial intention and identifying specific target traits for strengthening. The information can help faculty members to better understand student pharmacists in terms of their aptitude for entrepreneurial and intrapreneurial activities and proclivity for certain types of projects and assignments. The EIPQ can help students to better understand themselves and be selfaware of their inclinations and allow them to better prepare for future entrepreneurial or intrapreneurial ventures of interest. Other potential applications of EIPQ include as a screening tool for admission to the management track courses or aptitude for joint degree programs like the PharmD-MBA, and evaluation of student pharmacists' entrepreneurial and intrapreneurial intention post management courses.

\section{CONCLUSION}

A multi-dimensional questionnaire was constructed to measure the intentions of student pharmacists with regard to entrepreneurship and/or intrapreneurship. When implemented, it identified and confirmed a few key predictors of entrepreneurial and intrapreneurial intention among student pharmacists. This survey of entrepreneurial and intrapreneurial intention indicated that these pharmacy students were ambivalent about taking responsibility for pharmacy innovation. When fully validated, the EIPQ can be used in pharmacy schools for 


\section{American Journal of Pharmaceutical Education 2020; 84 (7) Article 7624.}

several purposes, including in the PharmD admission process to gain additional insights about candidates' potential to become future innovative entrepreneurial or intrapreneurial practitioners, and as a screening tool to determine students' aptitude for management tracks or PharmD-MBA programs.

\section{REFERENCES}

1. Hata M, Klotz R, Sylvies R, et al. Medication therapy management services provided by student pharmacists. Am J Pharm Educ. 2012;76(3):51. doi:10.5688/ajpe76351.

2. Hayes C, Hutchison LC. Development and evaluation of a studentled medicare part d planning clinic. Consult Pharm. 2013;28(4):

237-242. doi:10.4140/TCP.n.2013.237.

3. Lumpkin GT, Dess GG. Clarifying the entrepreneurial orientation construct and linking it to performance. Acad Manag Rev. 1996;

21(1):135-172. doi:10.5465/amr.1996.9602161568.

4. Mattingly TJ, Mullins CD, Melendez DR, Boyden K, Eddington ND. A systematic review of entrepreneurship in pharmacy practice and education. Am J Pharm Educ. 2019;83(3):7233. doi:10.5688/ ajpe 7233.

5. Hermansen-Kobulnicky CJ, Moss CL. Pharmacy student entrepreneurial orientation: a measure to identify potential pharmacist entrepreneurs. Am J Pharm Educ. 2004;68(5):113. doi:10.5688/aj6805113.

6. Mueller SL, Thomas AS. Culture and entrepreneurial potential: a nine country study of locus of control and innovativeness. $J$ Bus Ventur. 2001;16(1):51-75. doi:10.1016/S0883-9026(99)00039-7.

7. Manion, J. Enhancing career marketability through intrapreneurship. NAQ. Dec 2001.25(2):5-10. https://journals.lww.com/naqjournal/ Abstract/2001/01000/Enhancing_Career_Marketability_through.4.aspx. Accessed May 22, 2020.

8. Douglas EJ, Fitzsimmons JR. Intrapreneurial intentions versus entrepreneurial intentions: distinct constructs with different antecedents. Small Bus Econ. 2013;41(1):115-132. doi:10.1007/ s11187-012-9419-y.

9. American Pharmacists Association. Chain Community Pharmacy. APhA Career Pathway Evaluation Program for Pharmacy Professionals. APhA. 2013. https://www.pharmacist.com/sites/ default/files/files/Profile_06\%20Chain $\% 20$ pharmacy $\% 20$ Final $\%$ 20071713.pdfAccessed May 22, 2020.

10. Hohmeier KC, Gatwood J. Toward intrapreneurship in pharmacy education. Am J Pharm Educ. 2016;80(3):53. doi:10.5688/ajpe80353. 11. Schneider DN. A key pharmacy intrapreneurial program: ambulatory care. Top Hosp Pharm Manag. 1987;6(4):21-29. https:// pubmed.ncbi.nlm.nih.gov/10314208/. Accessed May 22, 2020.

12. Zellmer W. JCPP plans for following up on the conference. Joint Commission of Pharmacy Practitioners. Am J Heal Pharm. 2000;57(6). https://pubmed.ncbi.nlm.nih.gov/10754772/. Accessed May 22, 2020.

13. Accreditation Council for Pharmacy Education. Accreditation standards and key elements for the professional program in pharmacy leading to the doctor of pharmacy degree (Standards 2016). https:// www.acpe-accredit.org/pdf/Standards2016FINAL.pdf. Published February 2015. Accessed May 22, 2020.

14. Pharmacy and Medically Underserved Areas Enhancement Act ASHP. https://www.ashp.org/Advocacy-and-Issues/Provider-Status/ Pharmacy-and-Medically-Underserved-AreasEnhancementAct? loginreturnUrl= SSOCheck Only. Accessed May 22, 2020.
15. Tolle EM, Al Jumali AAA, Catney CM, McDonough RP, Veach S, Doucette WR. A survey of pharmacists' preparedness for provider status implementation. Am J Pharm Educ. 2017;57(3):S284-S288. doi:10.1016/j.japh.2017.02.022.

16. Gregory PAM, Whyte B, Austin Z. How do community pharmacists make decisions? results of an exploratory qualitative study in Ontario. Can Pharm J (Ott). 2016;149(2):90-98. doi:10.1177/1715163515625656.

17. Khan MU, Ahmad A, Fayyaz M, Ashraf N, Bhagavathula A. Exploring the intentions of pharmacy students towards pharmacy ownership by using theory of planned behaviour. BMC. 2016;9:183. doi:10.1186/s13104-016-1996-4.

18. Rosenthal M, Austin Z, Tsuyuki RT. Are pharmacists the ultimate barrier to pharmacy practice change? Can Pharm J (Ott). 2010;143(1):37-42. doi:10.3821/1913-701X-143.1.37.

19. Rosenthal MM, Breault RR, Austin Z, Tsuyuki RT. Pharmacists' self-perception of their professional role: insights into community pharmacy culture. J Am Pharm Assoc. 2011;51(3):363-368a. doi:10.1331/JAPhA.2011.10034.

20. Luetsch K. Attitudes and attributes of pharmacists in relation to practice change - a scoping review and discussion. Res Soc Adm Pharm. 2017;13(3):440-455.e11. doi:10.1016/j.sapharm.2016. 06.010 .

21. Willink DP, Isetts BJ. Becoming "indispensable": developing innovative community pharmacy practices. Am J Pharm Educ. 2003;45(3):376-386;387-389. https://pubmed.ncbi.nlm.nih.gov/ 15991760/. Accessed May 22, 2020.

22. Baum JR, Locke EA. The relationship of entrepreneurial traits, skill, and motivation to subsequent venture growth. J Appl Psychol. 2004;89(4):587-598. doi:10.1037/0021-9010.89.4.587.

23. Noble C, O'Brien M, Coombes I, Shaw PN, Nissen L, Clavarino A. Becoming a pharmacist: students' perceptions of their curricular experience and professional identity formation. Curr Pharm Teach Learn. 2014;6(3):327-339. doi:10.1016/j.cpt1.2014.02.010.

24. Rotter JB. Generalized expectancies for internal versus external locus of control of reinforcement. Psychol Monogr Gen Appl. 1966;80(1):1-28. doi:10.1037/h0092976.

25. Paunonen SV, Jackson DN. The Jackson Personality Inventory and the Five-Factor Model of Personality. J Res Pers.

1996;30(1):42-59. doi:10.1006/jrpe.1996.0003.

26. Vecchio RP. Entrepreneurship and leadership: common trends and common threads. Hum Resour Manag Rev. 2003;13(2):303-327. doi:10.1016/S1053-4822(03)00019-6.

27. Laverty G, Hanna L-A, Haughey S, Hughes C. Developing entrepreneurial skills in pharmacy students. Am J Pharm Educ. 2015;79(7):106. doi:10.5688/ajpe797106.

28. Ramia E, Salameh P, Btaiche IF, Saad AH. Mapping and assessment of personal and professional development skills in a pharmacy curriculum. BMC Med Educ. 2016;16(1):19. doi:10.1186/ s12909-016-0533-4.

29. Shahiwala A. Entrepreneurship skills development through project-based activity in bachelor of pharmacy program. Curr Pharm Teach Learn. 2017;9(4):698-706. doi:10.1016/j.cpt1.2017.03.017. 30. Seibert SE, Crant JM, Kraimer ML. Proactive personality and career success. J Appl Psychol. 1999;84(3):416.

31. Van Gelderen M, Brand M, van Praag M, Bodewes W, Poutsma E, Van Gils A. Explaining entrepreneurial intentions by means of the theory of planned behaviour. Career Dev Int. 2008;13(6):538-559. 32. Gomez-Mejia LR, Balkin DB. Effectiveness of individual and aggregate compensation strategies. Ind Relat (Berkeley). 1989; 28(3):431-445. doi:10.1111/j.1468-232X.1989.tb00736.x. 


\section{American Journal of Pharmaceutical Education 2020; 84 (7) Article 7624.}

33. Bateman TS, Crant JM. The proactive component of organizational behavior: a measure and correlates. J Organ Behav. 1993;14(2):103-118. doi:10.1002/job.4030140202.

34. Robinson GFWB, Switzer GE, Cohen ED, et al. Shortening the work preference inventory for use with physician scientists: wpi-10. Clin Transl Sci. 2014;7(4):324-328. doi:10.1111/cts.12132.

35. Filsinger EE. A measure of interpersonal orientation: the liking people scale. J Pers Assess. 1981;45(3):295-300. doi:10.1207/ s15327752jpa4503_11.

36. Altun $\mathrm{i}$. The perceived problem solving ability and values of student nurses and midwives. Nurse Educ Today. 2003;23(8):

575-584. doi:10.1016/S0260-6917(03)00096-0.

37. Bobbio A, Manganelli AM. Leadership self-efficacy scale: a new multidimensional instrument. TPM. 2009;16(1):3-24. http://

www.tpmap.org/wp-content/uploads/2014/11/16.1.1.pdf. Accessed June 6, 2020.

38. Miller D. The correlates of entrepreneurship in three types of firms. Manage Sci. 1983;29(7):770-791. doi:10.1287/mnsc.29.7.770. 39. IBM SPSS Statistics for Windows, Version 25.0. Armonk, NY: IBM Corp. http://www-01.ibm.com/support/docview.wss? uid=swg21476197. Published 2017. Accessed June 6, 2020. 40. StataCorp. 2017. Stata Statistical Software: Release 15. College Station. TX: StataCorp LLC. https://www.stata.com/support/faqs/ resources/citing-software-documentation-faqs/. Accessed June 6, 2020. 41. The University of North Carolina Eshelman School of Pharmacy. Medipreneurs. https://www.medipreneurs.com/. Accessed June 6, 2020 .

42. Thielemier B. 10 shared traits of successful pharmacist entrepreneurs. Pharmacy Times. https://www.pharmacytimes.com/ contributor/blair-thielemier-pharmd/2016/02/10-shared-traits-ofsuccessful-pharmacist-entrepreneurs/. Published February 4, 2016. Accessed June 6, 2020.

43. Douglas EJ, Shepherd DA. Self-employment as a career choice: attitudes, entrepreneurial intentions, and utility maximization. Entrep Theory Pract. 2002;26(3):81-90. doi:10.1177/104225870202600305. 44. Brown CM, Cantu R, Corbell Z, Roberts K. Attitudes and interests of pharmacists regarding independent pharmacy ownership. Am J Pharm Educ. 2007;47(2):174-180. doi:10.1331/D525-097021X5-8UU7.

45. Adamcik BA, Ransford HE, Oppenheimer PR, Brown JF, Eagan PA, Weissman FG. New clinical roles for pharmacists: a study of role expansion. Soc Sci Med. 1986;23(11):1187-1200. doi:10.1016/02779536(86)90338-2.

46. Pearson GJ. Evolution in the practice of pharmacy--not a revolution! CMAJ. 2007;176(9):1295-1296. doi:10.1503/cmaj.070041.
47. Cain J. A pharmacy elective course on creative thinking, innovation, and Ted talks. Am J Pharm Educ. 2016;80(10):170. doi:10.5688/ajpe8010170.

48. Caird $\mathrm{S}$. Testing enterprising tendency in occupational groups. Br J Manag. 1991;2(4):177-186. doi:10.1111/j.1467-8551.1991. tb00025.x.

49. Begley TM. Using founder status, age of firm, and company growth rate as the basis for distinguishing entrepreneurs from managers of smaller businesses. J Bus Ventur. 1995;10(3):249-263. doi:10.1016/0883-9026(94)00023-N.

50. Sexton DL, Bowman N. The entrepreneur: a capable executive and more. J Bus Ventur. 1985;1(1):129-140. doi:10.1016/08839026(85)90012-6.

51. Douglas E Fitzsimmons J. Individual intentions towards entrepreneurship vs. intrapreneurship. https://eprints.qut.edu.au/ 15293/1/AGSE_2008_-_Douglas.pdf. Accessed June 6, 2020.

52. Locke EA, Kirkpatrick S. The Essence of Leadership : The Four Keys to Leading Successfully. Lexington Books; 1999.

53. Yukl GA. Leadership in Organizations. 6th Edition. Amazon.com: Books;2006. https://www.amazon.com/LeadershipOrganizations-6th-Gary-Yukl/dp/B000OHSTYI. Accessed June 6, 2020.

54. Bruni A, Gherardi S, Poggoi B. Gender and entrepreneurship. An Ethnographic Approach. Taylor \& Francis Group. https:// www.taylorfrancis.com/books/9780429234743. Accessed June 6, 2020.

55. Fischer E, Reuber AR, Dyke L. A theoretical overview and extension of research on sex, gender, and entrepreneurship. $J$ Bus Venturing. 1993; 8(2):151-168. https://www.sciencedirect.com/ science/article/pii/088390269390017Y. Published March 1993. Published online 2002. Accessed June 6, 2020.

56. Ross JE, Ross JE, Unwalla D, Unwalla D. Who is an intrapreneur? Personnel. 1986;63(12):45-49.

57. Spinelli S, Adams R, Timmons JA. New Venture Creation: Entrepreneurship for the 21st Century. 2004; Vol. 6. New York: McGraw-Hill/Irwin. https://www.researchgate.net/publication/ 272682121_New_Venture_Creation. Accessed June 6, 2020.

58. Greer N, Bolduc J, Geurkink E, et al. Pharmacist-led chronic disease management: a systematic review of effectiveness and harms compared with usual care. Ann Intern Med. 2016;165(1):30. doi:10.7326/M15-3058.

59. Thielemier BG. How to Build a Pharmacy Consulting Business: Your Rx for Finding Freedom and Living Your Career. Blair Thielemier: CreateSpace Independent Publishing Platform; 2016. 